\title{
Interface argamassa-suporte: análise das características físicas com base em várias campanhas experimentais
}

\author{
Support-mortar interface: analysis of physical \\ characteristics based on several experimental \\ programmes
}

\begin{abstract}
Maria Isabel Morais Torres
Inês Flores-Colen

Dora Susana Gomes da Silveira

Rafael Travincas Pinto

Gina Maria Lourenço Matias

1, 2 Maria Isabel Morais Torres

1 Instituto de Invesrtigação e

Desenvolvimento Tecnológico para a

Construção, Energia, Ambiente e Sustentabilidade

2Universidade de Coimbra Coimbra - Portugal

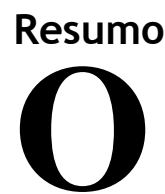

s revestimentos de paredes mais usados em Portugal, e mesmo ano âmbito europeu e mundial, continuam sendo as argamassas de revestimento, quer sejam à base de cal ou de cimento, quer sejam tradicionais, feitas em obra ou pré-doseadas. De acordo com a normalização disponível, o estudo de desempenho dessas argamassas é realizado sobre provetes produzidos em laboratório, com medidas normalizadas e em condições de cura e de ensaio pré-estabelecidas. No entanto, quando as argamassas são aplicadas sobre os suportes reais o seu comportamento final não será exatamente o mesmo. As dimensões, as condições de aplicação e as condições de cura são distintas. Assim, é consensual dizer que as características finais dos rebocos aplicados em condições reais de exposição serão distintas das obtidas em laboratório.O estudo que se pretende apresentar faz parte de uma investigação mais alargada no âmbito do projeto IF Mortar, em que se pretende analisar a influência das características de diversos suportes nas características de diferentes tipos de

${ }^{3}$ Inês Flores-Colen ${ }^{3}$ Universidade de Lisboa Lisboa - Portugal argamassa, para se prever, de forma mais rigorosa, qual o comportamento final das argamassas após sua aplicação.Neste artigo são apresentados alguns dos resultados já obtidos em campanhas experimentais, relativos às características físicas de diversas argamassas aplicadas sobre distintos suportes.
\end{abstract}

${ }^{4}$ Dora Susana Gomes da Silveira ${ }^{4}$ Instituto de Invesrtigação e Desenvolvimento Tecnológico para a Construção, Energia, Ambiente e Sustentabilidade Coimbra - Portugal

${ }^{5}$ Rafael Travincas Pinto ${ }^{5}$ Universidade de Lisboa Lisboa - Portugal

${ }^{6,} 7$ Gina Maria Lourenço Matias ${ }^{6}$ Instituto de Invesrtigação e Desenvolvimento Tecnológico para a Construção, Energia, Ambiente e Sustentabilidade

${ }^{7}$ Associação para o Desenvolvimento da Aerodinâmica Industrial, Laboratório Associado de Energia, Coimbra - Portugal

Recebido em 26/09/19 Aceito em 04/04/20

Palavras-chave: Argamassa. Suporte. Interface. Características físicas.

\section{Abstract}

The most commonly used wall coatings in Portugal, and alsoin the rest of Europe and the world, are still mortars, both lime-and cement- based, betheytraditional, on-site or pre-dosed. According to the currentstandards, performance studies on these mortars are carried out on laboratory-produced specimens, in standard dimensions, and under pre-established curing conditions and tests. However, when mortars are applied to real substrates, their final behaviour will not be the same. The dimensions, application conditions and curing conditions are different. It is, therefore, widelyagreedthatthe final characteristics of mortars applied under real exposure conditions will be different from those obtained in the laboratory. This study is part of a wider investigation in the scope of the IF Mortar project, which aims to analyse the influence of the characteristics of severaldifferent supports on the characteristics of different types of mortars, to more accurately predict the final behaviour of mortars after their application. This paper presents some of the results already obtained in experimental campaigns, concerning the physical characteristics of different mortars applied to different supports.

Keywords: Mortars. Suport influence. Interface. Physical Characteristics. 


\section{Introdução}

Os revestimentos de paredes mais usados continuam sendo as argamassas de revestimento, quer sejam à base de cal ou cimento, tradicionais ou pré-doseadas.

Nesses últimos anos muita investigação tem sido desenvolvida no sentido de aprofundar o conhecimento do comportamento dos diversos tipos de argamassas e do desenvolvimento de novos tipos de argamassas incorporando novos produtos, de forma a podermos sempre fazer as melhores escolhas, quer no que diz respeito ao tipo de argamassa a utilizar, quer no que diz respeito ao seu traço. O estudo das características das argamassas é quase sempre realizado em provetes executados em laboratório, com diversas configurações e de acordo com as exigências das respetivas normas. No entanto, o comportamento das argamassas dentro dos moldes laboratoriais não vai ser exatamente o mesmo que o comportamento das argamassas aplicadas sobre suportes reais, segundo Moropoulou, Bakolas e Bisbikou(2000).

Sabemos que a aderência entre fases é um dos principais indicadores de qualidade do desempenho de sistemas multifásicos. O comportamento das argamassas depende da aderência entre o suporte e a própria argamassa. Essa característica vai influenciar as propriedades da argamassa. Após a aplicação da argamassa no suporte forma-se uma interface, e as interações que ocorrem após o seu contato com o substrato vãose modificando ao longo do tempo, devido à cinética de hidratação e à absorção do substrato, como sugerido por Nicot (2008) e Costa e John (2011).

Segundo Wu (1982), em um sistema multifásico a aderência entre as diversas fases garante que as ações mecânicas sejam transferidas através da interface. As forças interfaciais e as propriedades da interface e de ambas as fases condicionam a resistência mecânica do sistema.

Em sistemas cimentícios multifásicos, como é o caso de uma argamassa aplicada sobre um suporte, coexiste uma zona de transição entre as fases garantida por uma aderência que pode ser uma aderência química ou mecânica, de acordo com Costa e Hohn (2011).

Nicot (2008) define aderência mecânica como "[...] a capacidade da argamassa penetrar no suporte através da porosidade e da rugosidade do mesmo [...]" e é dependente das características superficiais do suporte. De fato, se estivermos perante superfícies lisas e sem poros, o que vai ocorrer é uma aderência essencialmente química, pois não há qualquer penetração da argamassa no suporte. Por outro lado, se o suporte tiver porosidade aberta ou rugosidade que permitam essa penetração, poderemos ter aderência mecânica. Na aderência argamassa-alvenaria, esse tem sido considerado o principal mecanismo de aderência, de acordo com Carvalho Junior (2002), e pode ser descrito como um sistema complexo envolvendo o transporte de fluidos e de finos para a zona de transição, a que se segue a hidratação dos materiais cimentícios. O que se verifica é a penetração das partículas mais finas da pasta de argamassa nos poros do suporte. Quando se dá o contato da argamassa, no seu estado plástico, com o suporte poroso, parte da água de amassamento contendo dissolvidos componentes do aglomerante é absorvida pelo suporte e penetra nos seus poros e/ou rugosidades. Já no interior dos poros do suporte vão ocorrer os fenômenos de hidratação do cimento/cal (POLITO; CARVALHO JUNIOR; BRANDÃO, 2010).

De acordo com Moropoulou, Bakolas e Bisbikoun (2000), o comportamento da argamassa é assim influenciado pelas características do suporte e da interface que se vai criar entre estes dois elementos.

Vários autores (PALMER; PARSON, 1934; AGUIAR; CRUZ, 1998; CARVALHO JUNIOR, 2002; COSTA; CARASEK, 2009; SZEMEREY-KISS; TÖRÖK, 2017) têmse debruçado sobre o estudo da interface argamassa-suporte e dos fatores que influenciam a aderência entre esses dois elementos. No entanto, no que diz respeito à investigação sobre a alteração das características das argamassas após aplicação nos suportes, ainda são escassos os trabalhos de investigação.

Quais serão os parâmetros que irão influenciar esse comportamento? Terão maior influência as características das argamassas ou as características do suporte? De que forma essas características irão influenciar o comportamento das argamassas? Terão as condições de aplicação e de cura alguma influência? Irão as características das argamassas aplicadas alterar-se ao longo do tempo de forma diferente, conforme o tipo de suporte? São essas algumas das perguntas a que ainda, hoje em dia, não sabemos responder com rigor.

O presente estudo faz parte de uma investigação no âmbito do projeto IF Mortar, em que se pretende analisar a influência das propriedades dos suportes nas características das argamassas, para se prever, de forma mais rigorosa, o comportamento das argamassas após aplicação.

332 Torres, M. I. M.; Flores-Colen, I.; Silveira, D. S. G. da; Pinto, R. T.; Matias, G. M. L. 


\section{Campanhas experimentais}

\section{Objetivos}

Foram já desenvolvidas algumas campanhas experimentais, que tiveram como principal objetivo estudar a influência de características dos suportes, condições de aplicação e condições de cura nas características das argamassas de revestimento. Para tal, foram considerados diferentes tipos de suporte e de argamassas. Adotaram-se também distintas condições de aplicação, em termos de preparação prévia do suporte, número de camadas e espessura da argamassa. Em um dos trabalhos os ensaios foram realizados após cura corrente e também após envelhecimento acelerado.

\section{Campanhas experimentais}

Campanha C1 - No trabalho desenvolvido por Gonçalves (2010) utilizaram-se dois tipos de argamassa: uma argamassa tradicional de cimento (traço 1:4, em volume) e uma monocamada pré-dosada. Os suportes escolhidos foram placas de concreto e tijolos cerâmicos furados.

Para a caracterização inicial das argamassas, realizaram-se provetes prismáticos $\left(40 \times 40 \times 160 \mathrm{~mm}^{3}\right), \mathrm{de}^{2}$ acordo com as normas aplicáveis. Para a avaliação do desempenho em serviço, as argamassas foram aplicadas nos dois tipos de suporte, tendo sido previamente pulverizados com água.A aplicação das argamassas em ambos os suportes foi executada com o auxílio da colher de pedreiro, exercendo-se certa pressão, de modo a garantir a aderência entre os dois materiais, e em seguida, com uma talocha, procedeu-se ao acabamento da argamassa através do alisamento final da superfície. Com a argamassa tradicional estudou-se a influência do número de camadas, fazendo variar esse fator (uma, duas e três camadas) e mantendo constante a espessura total $(3 \mathrm{~cm})$. Foi necessário aguardar uma semana entre a aplicação das diversas camadas para a argamassa ganhar alguma consistência. A influência da espessura foi avaliada com a monocamada, utilizando-se duas espessuras distintas $(1,5 \mathrm{~cm}$ e $3 \mathrm{~cm})$. As argamassas endurecidas nos moldes e as argamassas endurecidas nos suportes foram sujeitas a condições de cura semelhantes e foram as seguintes: 7 dias em saco de polietileno selado, em sala a $25^{\circ} \mathrm{C}$ e $65 \% \mathrm{HR}$, restantes dias até à primeira data de ensaio, em sala a $25^{\circ} \mathrm{C}$ e $65 \% \mathrm{HR}$ (ensaios aos 28 e 60 dias para as argamassas endurecidas nos moldes; ensaios aos 28, 60 e 90 dias para as argamassas endurecidas nos suportes).

A caracterização das argamassas foi efetuada no estado fresco e no estado endurecido. No estado fresco avaliou-se a consistência por espalhamento e a massa volúmica aparente. A caracterização no estado endurecido (endurecimento nos moldes) foi feita aos 28 e 60 dias de idade, tendo-se avaliado as seguintes características:
(a) massa volúmica aparente;
(b) resistência à flexão e compressão;
(c) módulo de elasticidade dinâmico; e
(d) absorção de água por capilaridade.

Para a avaliação do desempenho das argamassas aplicadas nos suportes recorreu-se a técnicas geralmente utilizadas in situ, avaliando-se:

(a) o índice esclerométrico, com recurso ao esclerômetro pendular (Figura 1a);

(b) a velocidade aparente de propagação de ultrassons (método indireto) (Figura 1b); e

(c) a permeabilidade à água líquida, através do método dos tubos de Karsten (Figura 1c).

Essa caracterização foi feita aos 28, 60 e 90 dias de idade. 
Figura 1 - Avaliação do desempenho das argamassas aplicadas nos suportes: ensaio esclerométrico, ensaio dos ultrassons, ensaio com tubos de Karsten

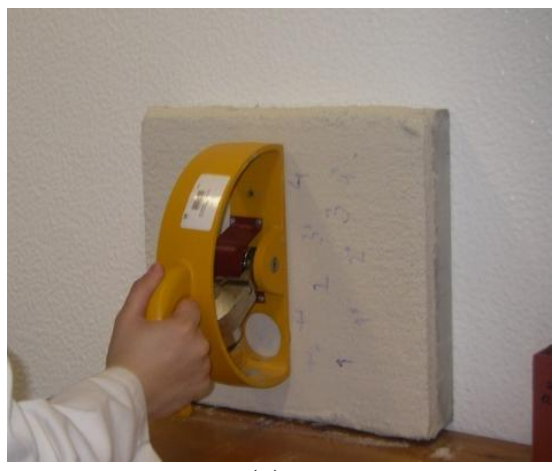

(a)

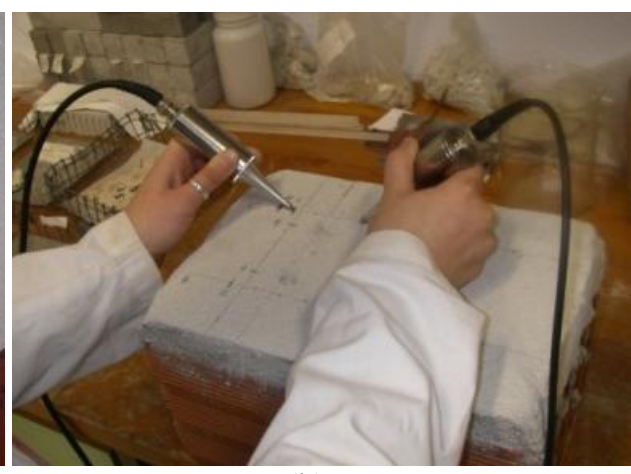

(b)

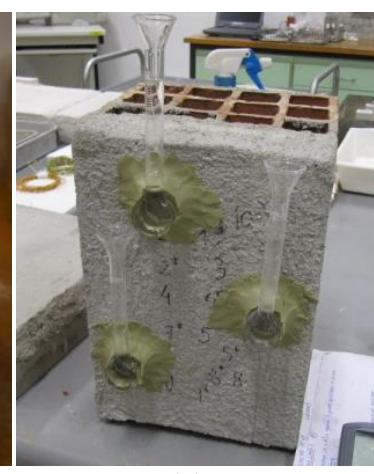

(c)

Fonte: Gonçalves (2010).

Campanha $C 2$ - O trabalho de Arromba (2011) foi desenvolvido na sequência do trabalho anterior, tendo utilizado as mesmas argamassas e suportes. Para a caracterização inicial das argamassas, realizaram-se também provetes prismáticos $\left(40 \times 40 \times 160 \mathrm{~mm}^{3}\right)$. Para a avaliação do desempenho em serviço, as argamassas foram aplicadas nos dois tipos de suporte, com uma camada com $2 \mathrm{~cm}$ de espessura, adotando-se diferentes condições iniciais da superfície do suporte: sem umedecimento, com pulverização dupla de água e com imersão em água. As condições de cura foram as seguintes: 7 dias em saco de polietileno selado, em sala a $20{ }^{\circ} \mathrm{C}$ e $65 \% \mathrm{HR}$, restantes dias até à primeira data de ensaio, em sala a $20{ }^{\circ} \mathrm{C}$ e $65 \%$ HR.A aplicação das argamassas em ambos os suportes foi executada com o auxílio da colher de pedreiro, exercendo-se certa pressão, de modo a garantir a aderência entre os dois materiais, e em seguida, com uma talocha, procedeu-se ao acabamento da argamassa através do alisamento final da superfície.

Inicialmente, realizou-se a caracterização dos dois tipos de suporte quanto à absorção de água por capilaridade. A caracterização das argamassas no estado fresco consistiu na avaliação da consistência por espalhamento e massa volúmica aparente. As argamassas no estado endurecido (endurecimento nos moldes) foram ensaiadas aos 28 e 90 dias, tendo-se avaliado as seguintes características:

(a) massa volúmica aparente;

(b) porosidade aberta;

(c) módulo de elasticidade dinâmico; e

(d) absorção de água por capilaridade.

Para a avaliação do desempenho das argamassas aplicadas nos suportes recorreu-se às mesmas técnicas utilizadas por Gonçalves (2010) (isto é, esclerômetro pendular, ultrassons e tubos de Karsten), tendo essa avaliação sido realizada aos 28 e 90 dias de idade.

Em uma fase posterior, foram preparados modelos com suportes preparados com pulverização dupla de água (pulverização com $20 \mathrm{ml}$ e $25 \mathrm{ml}$ de água, para suportes de tijolo e de concreto, respetivamente) e com a utilização de uma rede plástica colocada entre o suporte e a argamassa. Após o tempo de cura, a camada de revestimento foi destacada de cada modelo (Figura 2a). A partir de parte dessa camada cortaram-se pequenos prismas $\left(20 \times 20 \times 40 \mathrm{~mm}^{3}\right.$ ) (Figura 2b), que foram sujeitos a ensaios de absorção de água por capilaridade e a pesagem hidrostática para determinação da porosidade aberta. A restante parte da camada de revestimento destinou-se à realização de ensaios com esclerômetro pendular e ultrassons. A caracterização das argamassas destacadas dos suportes foi feita aos 28 e 90 dias de idade. Por fim, realizaram-se ainda ensaios de aderência ao suporte, em modelos com suportes preparados com pulverização dupla de água, aos 100 dias de idade.

Campanha C3 - Torres (2014), para a sua investigação, escolheu três tipos de suportes e três tipos de argamassas. Os suportes selecionados foram o tijolo e o concreto, por serem suportes correntemente utilizados na nossa construção. O terceiro tipo de suporte foi escolhido por ser um suporte pouco absorvente - a capacidade de absorção do suporte tem bastante influência na aderência da argamassa -, e a opção foi a chapa acrílica. Quanto ao tipo de argamassa, a opção foi uma argamassa de cimento (traço 1:3, em volume) formulada em laboratório e uma argamassa de cal aérea e uma monocamada pré-dosadas. 

Figura 2 - Camada de revestimento após separação do suporte e prismas resultantes do corte do
revestimento

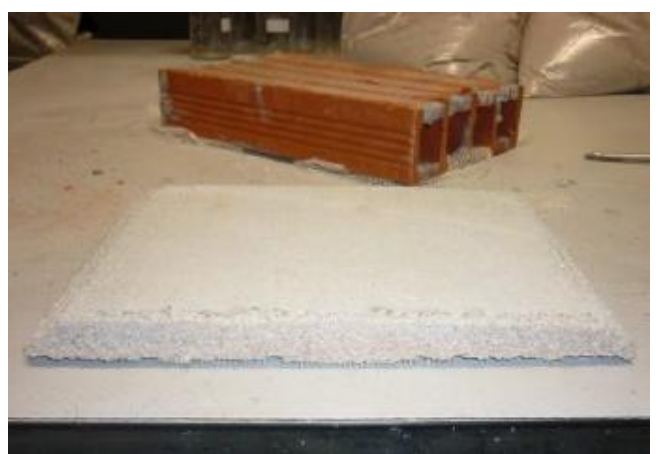

(a)

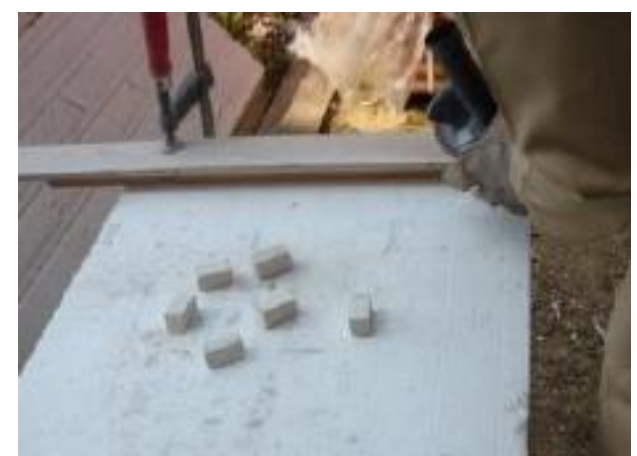

(b)

Fonte: Arromba (2011).

A caracterização das argamassas, quer no estado fresco quer endurecido, foi desenvolvida determinando-se a sua consistência, massa volúmica aparente, porosidade aberta, absorção de água por capilaridade, fluxo de secagem, permeabilidade ao vapor da água, resistência à compressão, resistência à flexão e módulo de elasticidade. A primeira caracterização foi feita em provetes prismáticos com 40x40x160 mm³ e cilíndricos com 1,5 cm de espessura e $10 \mathrm{~cm}$ de diâmetro, executados em laboratório e de acordo com a normalização aplicável. Seguiu-se a aplicação de uma camada de $1,5 \mathrm{~cm}$ de espessura de argamassa nos diversos suportes. A aplicação das argamassas em ambos os suportes foi executada com o auxílio da colher de pedreiro, exercendo certa pressão, de modo a garantir a aderência entre os dois materiais, e em seguida, com uma talocha, procedeu-se ao acabamento da argamassa através do alisamento final da superfície. Os ensaios realizados sobre as argamassas aplicadas nos suportes dividiram-se em duas etapas: aplicação sobre o suporte sem qualquer tratamento prévio e umidificação do suporte por pulverização. Os ensaios foram executados em duas fases: após condições de cura corrente e após envelhecimento acelerado, de acordo com as seguintes condições:

(a) condições de cura corrente: 7 dias em saco de polietileno selado, em sala a $20{ }^{\circ} \mathrm{C}$ e $65 \% \mathrm{HR}$, restantes dias até à primeira data de ensaio, em sala a $20{ }^{\circ} \mathrm{C}$ e $65 \% \mathrm{HR}$; e

(b) envelhecimento acelerado, de acordo com a EN 1015-21 (COMITÉ..., 2002b): cura inicial de 28 dias (condições de cura corrente enunciadas em cima). Após essa cura inicial duas séries de condicionamento de quatro ciclos:

- $1^{\mathrm{a}}$ série: quatro ciclos:

. colocar a $60 \pm 2^{\circ} \mathrm{C}$ durante $8 \mathrm{~h} \pm 15 \mathrm{~min}$;

. colocar a $20 \pm 2{ }^{\circ} \mathrm{C} / 65 \pm 5 \%$ HR durante $30 \mathrm{~min} \pm 2 \mathrm{~min}$;

. colocar a $-15 \pm 1^{\circ} \mathrm{C}$ durante $15 \mathrm{~min} \pm 15 \mathrm{~min}$; e

. colocar a $20 \pm 2{ }^{\circ} \mathrm{C} / 65 \pm 5 \%$ HR durante $30 \mathrm{~min} \pm 2 \mathrm{~min}$.

- $2^{\mathrm{a}}$ série: quatro ciclos:

. emergir parcialmente $(5 \mathrm{~mm})$ os provetes com a face rebocada na água a $20 \pm 1{ }^{\circ} \mathrm{C}$ durante $8 \mathrm{~h} \pm 15 \mathrm{~min}$;

. colocar a $20 \pm 2{ }^{\circ} \mathrm{C} / 65 \pm 5 \%$ HR durante $30 \mathrm{~min} \pm 2 \mathrm{~min}$;

. colocar a $-15 \pm 1^{\circ} \mathrm{C}$ durante $15 \mathrm{~min} \pm 15 \mathrm{~min}$; e

. colocar a $20 \pm 2{ }^{\circ} \mathrm{C} / 65 \pm 5 \% \mathrm{HR}$ durante $30 \mathrm{~min} \pm 2 \mathrm{~min}$.

Decorridos os diversos tempos de cura/envelhecimento acelerado, a camada de argamassa de alguns dos provetes foi destacada dos respetivos suportes e foram cortados diversos provetes para a caracterização das argamassas. O destacamento da camada de argamassa do suporte foi facilitado pela introdução de uma rede entre a argamassa e o suporte (Figuras 3 e 4). Procedeu-se à caracterização das argamassas destacadas dos suportes através da determinação da massa volúmica aparente, porosidade aberta, permeabilidade ao vapor de água, absorção de água por capilaridade, índice de secagem e resistência à compressão. 
Figura 3 - Aplicação da camada de rede nos provetes

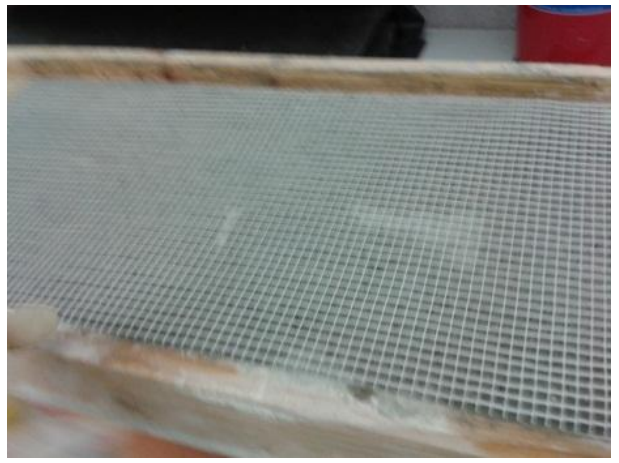

(a)

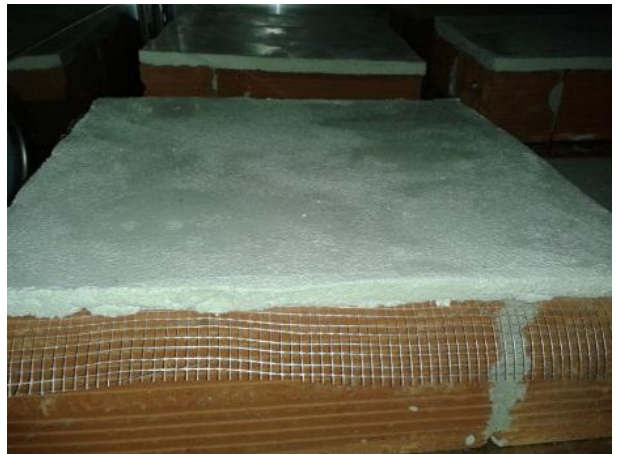

(b)

Figura 4 - Corte dos provetes das argamassas aplicadas nos suportes

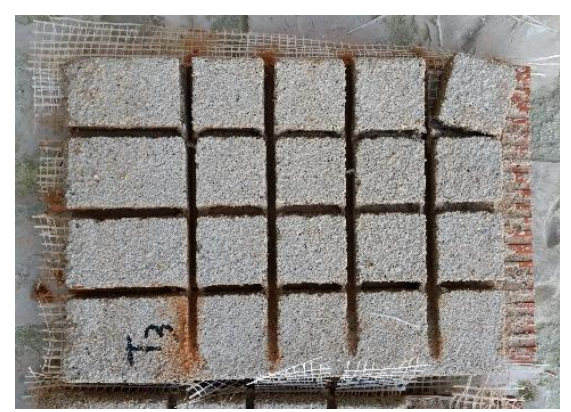

(a)

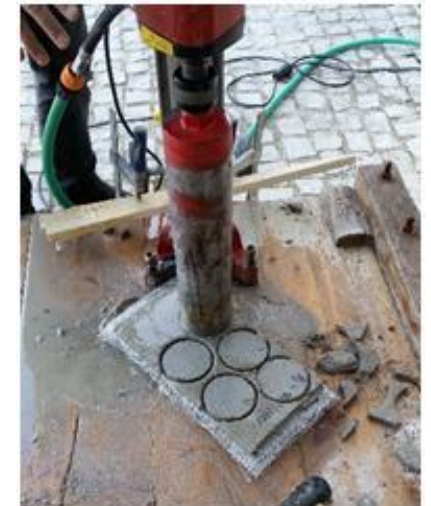

(b)

Campanha C4 - Na sequência do trabalho anterior e com metodologia de desenvolvimento idêntica, Paulo (2019) analisou uma argamassa de cimento formulada em laboratório com um traço de 1:4 e uma argamassa de cal hidráulica natural, também formulada em laboratório e com um traço de 1:3. Quanto aos suportes, mantiveram-se dois dos analisados anteriormente: o tijolo vazado e as placas de concreto. Com este trabalho pretendeu-se analisar a influência do tratamento prévio da superfície dos suportes. Assim, em parte dos suportes foi aplicado um chapisco com a própria argamassa e os outros foram simplesmente umedecidos. Em ambos os casos três dias após a aplicação do chapisco foi aplicada a camada de argamassa. Nesse caso as condições de cura foram apenas a cura normal: 7 dias em saco de polietileno selado, em sala a $20{ }^{\circ} \mathrm{C}$ e $65 \% \mathrm{HR}$, restantes dias até à primeira data de ensaio, em sala a $20{ }^{\circ} \mathrm{C}$ e $65 \% \mathrm{HR}$.

\section{Materiais}

Os materiais selecionados nas várias campanhas experimentais e as respetivas condições de preparação e aplicação são os sintetizados na Tabela 1.

\section{Ensaios de caracterização física}

Nas campanhas experimentais desenvolvidas foram realizados ensaios de caracterização física dos suportes e das argamassas. As características físicas avaliadas nos trabalhos referidos encontram-se indicadas na Tabela 2. Todos os ensaios de caracterização das argamassas foram executados segundo as normas aplicáveis, exceto para as argamassas destacadas dos suportes. Nesses casos, como as dimensões dos provetes estavam limitadas à espessura da camada de argamassa aplicada, os procedimentos de ensaio tiveram de ser adaptados a essa realidade. 


\section{Resultados}

\section{Caracterização dos suportes}

Nos trabalhos C2 e C3 foi feita a caracterização inicial dos suportes. Verificou-se que o tijolo apresenta uma porosidade aberta (valor médio: 19,1\%) cerca de 50\% superior à do concreto (valor médio: 12,6\%) e uma massa volúmica aparente (valor médio: $2.026 \mathrm{~kg} / \mathrm{m}^{3}$ ) cerca de $10 \%$ menor que o concreto (valor médio: $2.247 \mathrm{~kg} / \mathrm{m}^{3}$ ). A massa volúmica e a porosidade aberta do acrílico são significativamente inferiores às do tijolo e do concreto (cerca de $45 \%$ e $98 \%$ inferiores, respetivamente). Observou-se, ainda, que a absorção de água por capilaridade e a permeabilidade ao vapor de água dos suportes estão diretamente relacionadas com a porosidade, sendo tanto maiores quanto maior é esse parâmetro.

\section{Caracterização das argamassas endurecidas nos moldes}

A caracterização das argamassas endurecidas nos moldes foi feita em todos os trabalhos. As argamassas tradicionais (de cimento ou cal hidráulica) apresentam valores médios de massa volúmica aparente que variam entre $1.807 \mathrm{~kg} / \mathrm{m}^{3}$ e $1.919 \mathrm{~kg} / \mathrm{m}^{3}$, sendo esses valores $23 \%$ superiores (em média) aos das argamassas pré-doseadas (de cimento ou cal área), que variam entre $1.376 \mathrm{~kg} / \mathrm{m}^{3}$ e $1.586 \mathrm{~kg} / \mathrm{m}^{3}$. A porosidade aberta $(\varepsilon)$ é maior para a argamassa pré-doseada de cal aérea $\left(\varepsilon_{\text {média }}=30 \%\right)$, seguida da tradicional de cal hidráulica $\left(\varepsilon_{\text {média }}=24 \%\right)$, pré-dosada de cimento $\left(\varepsilon_{\text {média }}=23 \%\right)$ e tradicional de cimento $\left(\varepsilon_{\text {média }}=20 \%\right)$. No que diz respeito à absorção de água por capilaridade, as argamassas pré-dosadas de cimento apresentam os menores valores (valores médios entre $0,05 \mathrm{~kg} /\left(\mathrm{m}^{2} \mathrm{~s}^{0,5}\right)$ e $0,12 \mathrm{~kg} /\left(\mathrm{m}^{2} \mathrm{~s}^{0,5}\right)$, seguidos das argamassas tradicionais de cimento (valores médios entre $0,28 \mathrm{~kg} /\left(\mathrm{m}^{2} \mathrm{~s}^{0,5}\right)$ e $1,21 \mathrm{~kg} /\left(\mathrm{m}^{2} \mathrm{~s}^{0,5}\right)$ ). A argamassa pré-dosada de cal aérea e a argamassa tradicional de cal hidráulica apresentam os maiores valores de absorção de água (valores médios entre $0,48 \mathrm{~kg} /\left(\mathrm{m}^{2} \mathrm{~s}^{0,5}\right)$ e $\left.1,9 \mathrm{~kg} /\left(\mathrm{m}^{2} \mathrm{~s}^{0,5}\right)\right)$, ainda que, para a argamassa pré-dosada de cal aérea, esse valor seja mais baixo que o habitual para argamassas tradicionais desse tipo (valores correntes entre 1,51 e 1,59 $\mathrm{kg} /\left(\mathrm{m}^{2} \mathrm{~s}^{0,5}\right)$, de acordo com Matias (2014)), o que poderá indicar a presença de hidrófugos na sua composição. O melhor comportamento das argamassas pré-dosadas de cimento deverá também justificar-se pelo uso de hidrófugos. Verificou-se ainda uma relação direta da permeabilidade ao vapor de água $(\delta)$ com a porosidade aberta, sendo esta maior para as argamassas de cal $\left(\delta_{\text {média }}=1,74 \times 10-11 \mathrm{~kg} /(\mathrm{msPa})\right)$, seguidas da argamassa pré-dosada de cimento $\left(\delta_{\text {média }}=1,36 \times 10-11 \mathrm{~kg} /(\mathrm{msPa})\right)$ e, por fim, da argamassa tradicional de cimento $\left(\delta_{\text {média }}=0,78 \times 10-11 \mathrm{~kg} /(\mathrm{msPa})\right)$.

Tabela 1 - Materiais e condições de aplicação

\begin{tabular}{|c|c|c|c|c|c|c|}
\hline & & & \multicolumn{4}{|c|}{ Campanhas experimentais } \\
\hline & & & C1 & $\mathbf{C 2}$ & C3 & $\mathrm{C4}$ \\
\hline \multirow{7}{*}{ 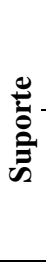 } & \multirow{3}{*}{ Tipo } & Concreto & $\mathrm{X}$ & $\mathrm{X}$ & $\mathrm{X}$ & $\mathrm{X}$ \\
\hline & & Tijolo furado & $\mathrm{X}$ & $X$ & $X$ & $\mathrm{X}$ \\
\hline & & Chapa acrílica & & & X & \\
\hline & \multirow{4}{*}{ Preparação } & Sem tratamento prévio & & $\mathrm{X}$ & $X$ & \\
\hline & & Umedecimento prévio & $\mathrm{X}$ & $\mathrm{X}$ & $\mathrm{X}$ & $\mathrm{X}$ \\
\hline & & Imersão prévia em água & & $\mathrm{X}$ & & \\
\hline & & Aplicação de chapisco & & & & $\mathrm{X}$ \\
\hline \multirow{10}{*}{ 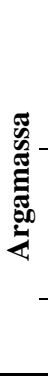 } & \multirow{4}{*}{ Tipo } & Cimento Portland do tipo II-32,5 & $\mathrm{X}$ & $\mathrm{X}$ & $X$ & $X$ \\
\hline & & Cal hidráulica (tradicional) & & & & $\mathrm{X}$ \\
\hline & & Cal aérea (pré-dosada) & & & $\mathrm{X}$ & \\
\hline & & Cimento (pré-dosada) & X & $\mathrm{X}$ & X & \\
\hline & \multirow{4}{*}{ Camadas e espessura } & 1 camada & $\mathrm{X}$ & $\mathrm{X}$ & $\mathrm{X}$ & $\mathrm{X}$ \\
\hline & & 2 camadas & $\mathrm{X}$ & & & \\
\hline & & 3 camadas & $\mathrm{X}$ & & & \\
\hline & & Espessura total $(\mathrm{cm})$ & $1,5 / 3$ & 2 & 1,5 & 1,5 \\
\hline & \multirow{2}{*}{ Condiçõos de cura } & Cura corrente & $\mathrm{X}^{\mathrm{a}}$ & $\mathrm{X}^{\mathrm{b}}$ & $\mathrm{X}^{\mathrm{b}}$ & $\mathrm{X}^{\mathrm{b}}$ \\
\hline & & Envelhecimento acelerado & & & $\mathrm{X}$ & \\
\hline
\end{tabular}

Nota: a durante 7 dias, em saco de polietileno selado, em sala a $25^{\circ} \mathrm{C}$ e $65 \% \mathrm{HR}$; durante os restantes dias até à primeira data de ensaio, em sala a $25{ }^{\circ} \mathrm{C}$ e $65 \%$ HR (ensaios aos 28 e 60 dias para as argamassas endurecidas nos moldes; ensaios

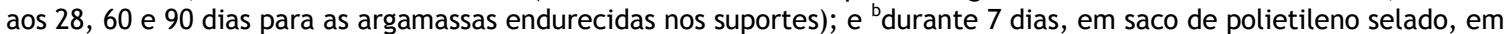
sala a $20{ }^{\circ} \mathrm{C}$ e $65 \% \mathrm{HR}$; durante os restantes dias até à primeira data de ensaio, em sala a $20{ }^{\circ} \mathrm{C}$ e $65 \% \mathrm{HR}$ (C2: ensaios aos 28 e 90 dias; $C 3$ e C4: ensaios aos 28 dias). 
Tabela 2 - Características físicas avaliadas e respectivas normas ou recomendações de ensaio

\begin{tabular}{|c|c|c|c|c|c|c|c|}
\hline & Materiais & Caracterização & Normas / recomendações & & Cam & $\begin{array}{l}\text { nha: } \\
\text { enta }\end{array}$ & \\
\hline & & & & $\mathbf{C}$ & $\mathrm{C2}$ & C3 & C4 \\
\hline & & $\begin{array}{l}\text { Massa volúmica } \\
\text { aparente }\end{array}$ & $\begin{array}{l}\text { NP EN } 1936 \text { (INSTITUTO..., } \\
\text { 2008) }\end{array}$ & & & $\mathrm{X}$ & \\
\hline & & Porosidade aberta & $\begin{array}{l}\text { NP EN } 1936 \text { (INSTITUTO..., } \\
\text { 2008) }\end{array}$ & & & $X$ & \\
\hline ڤั) & & $\begin{array}{l}\text { Absorção de água } \\
\text { por capilaridade }\end{array}$ & $\begin{array}{l}\text { ISO } 15148 \\
\text { (INTERNATIONAL..., 2002) } \\
\text { e EN 772-11 (COMITÉ..., } \\
\text { 2000) }\end{array}$ & & $\mathrm{X}$ & $\mathrm{X}$ & \\
\hline & & $\begin{array}{l}\text { Permeabilidade ao } \\
\text { vapor de água }\end{array}$ & $\begin{array}{l}\text { EN ISO } 12572 \text { (COMITÉ..., } \\
\text { 2001) }\end{array}$ & & & $\mathrm{X}$ & \\
\hline & & $\begin{array}{l}\text { Massa volúmica } \\
\text { aparente }\end{array}$ & $\begin{array}{l}\text { NP EN } 1936 \text { (INSTITUTO..., } \\
\text { 2008) e EN 1015-10 } \\
\text { (COMITÉ..., 1999) }\end{array}$ & $\mathrm{X}$ & $\mathrm{X}$ & $\mathrm{X}$ & $\mathrm{X}$ \\
\hline & & Porosidade aberta & $\begin{array}{l}\text { NP EN } 1936 \text { (INSTITUTO..., } \\
\text { 2008) }\end{array}$ & & & $\mathrm{X}$ & $X$ \\
\hline & $\begin{array}{l}\text { Endurecida } \\
\text { nos moldes }\end{array}$ & $\begin{array}{l}\text { Absorção de água } \\
\text { por capilaridade }\end{array}$ & $\begin{array}{l}\text { ISO } 15148 \\
\text { (INTERNATIONAL..., 2002), } \\
\text { EN 1015-18 (COMITÉ..., } \\
\text { 2002a) e EN } 15801 \text { (comité..., } \\
\text { 2009) }\end{array}$ & $\mathrm{X}$ & $X$ & $\mathrm{X}$ & $\mathrm{X}$ \\
\hline & & Índice de secagem & EN 16322 (COMITÉ..., 2013) & & & X & $\mathrm{X}$ \\
\hline F & & $\begin{array}{l}\text { Permeabilidade ao } \\
\text { vapor de água }\end{array}$ & $\begin{array}{l}\text { EN 1015-19 (COMITÉ..., } \\
\text { 1998) }\end{array}$ & & & $\mathrm{X}$ & $\mathrm{X}$ \\
\hline 总 & $\begin{array}{l}\text { Endurecida } \\
\text { no suporte } \\
\text { (não } \\
\text { destacada) }\end{array}$ & $\begin{array}{l}\text { Permeabilidade à } \\
\text { água líquida }\end{array}$ & $\begin{array}{l}\text { Ficha de ensaio FE Pa } 39.1 \text { do } \\
\text { LNEC (LABORATÓRIO..., } \\
\text { 2002) }\end{array}$ & $X$ & $\mathrm{X}$ & $\mathrm{X}$ & \\
\hline & & $\begin{array}{l}\text { Massa volúmica } \\
\text { aparente }\end{array}$ & $\begin{array}{l}\text { NP EN } 1936 \text { (INSTITUTO..., } \\
\text { 2008) }\end{array}$ & & & $X$ & $\mathrm{X}$ \\
\hline & & Porosidade aberta & $\begin{array}{l}\text { NP EN } 1936 \text { (INSTITUTO..., } \\
2008 \text { ) }\end{array}$ & & $\mathrm{X}$ & $\mathrm{X}$ & $X$ \\
\hline & $\begin{array}{l}\text { Endurecida } \\
\text { no suporte e } \\
\text { destacada }\end{array}$ & $\begin{array}{l}\text { Absorção de água } \\
\text { por capilaridade }\end{array}$ & $\begin{array}{l}\text { ISO } 15148 \\
\text { (INTERNATIONAL..., 2002), } \\
\text { EN 1015-18 (COMITÉ..., } \\
\text { 2002a) e EN } 15801 \\
\text { (COMITÉ..., 2009) }\end{array}$ & & $\mathrm{X}$ & $X$ & $\mathrm{X}$ \\
\hline & & Indice de secagem & EN 16322 (COMITÉ..., 2013) & & & $\mathrm{X}$ & $\mathrm{X}$ \\
\hline & & $\begin{array}{l}\text { Permeabilidade ao } \\
\text { vapor de água }\end{array}$ & $\begin{array}{l}\text { EN 1015-19 (COMITÉ..., } \\
\text { 1998) }\end{array}$ & & & $\mathrm{X}$ & $\mathrm{X}$ \\
\hline
\end{tabular}

\section{Comparação das argamassas endurecidas nos suportes com as argamassas endurecidas nos moldes}

(a) porosidade aberta e massa volúmica- nos trabalhos $\mathrm{C} 3$ e C4, verificou-se que a aplicação das argamassas nos suportes leva a uma redução (de $2 \%$ a 56\%) da sua porosidade aberta e também a um ligeiro aumento (até 6\%) da massa volúmica aparente. De fato, quando em contato com um substrato poroso, as argamassas no estado fresco são sujeitas a uma sucção da água de amassamento, que transporta consigo partículas finas da argamassa. A redução da quantidade de água e a pressão nas paredes dos poros provoca uma diminuição da porosidade aberta e, consequentemente, um aumento da massa volúmica em estado endurecido. Constatou-se que essa alteração tende a ser maior para as argamassas de cal - com reduções da porosidade aberta entre $19 \%$ e $56 \%$ - e menor para as argamassas de cimento - com reduções entre $2 \%$ e 29\%. Observou-se ainda que quanto maior é a capacidade de absorção de água do suporte, maior será a 
diminuição da porosidade aberta da argamassa. Assim, as argamassas aplicadas no suporte de tijolo registraram geralmente a maior diminuição de porosidade (reduções de $21 \%$ a 56\%), ou seja, ficaram mais compactas após aplicação. Para as argamassas pré-dosadas de cimento, no entanto, não se observou uma tendência tão clara;

(b) coeficiente de absorção de água e permeabilidade à água líquida - nos trabalhos C2, C3 e C4 verificouse que a absorção de água por capilaridade da argamassa diminui quando esta é aplicada no suporte (na maioria dos casos, reduções de $65 \%$ a $90 \%$ ), sendo que essa diminuição é mais significativa para os suportes mais porosos. Esse comportamento é consistente com a tendência verificada para a porosidade aberta. Essa tendência, no entanto, não se verificou para a argamassa pré-dosada de cimento estudada em $\mathrm{C} 3$, muito possivelmente devido à presença de hidrófugos na sua composição. Nos trabalhos C1, C2 e C3 fez-se também o ensaio de permeabilidade à água líquida sobre as argamassas endurecidas nos suportes (não destacadas), tendo-se observado uma tendência semelhante à verificada para o coeficiente de absorção de água - isto é, a permeabilidade à água líquida das argamassas aplicadas no suporte de tijolo, mais poroso, é inferior (de $65 \%$ a $82 \%$ ) à das argamassas aplicadas no concreto; e

(c) permeabilidade ao vapor de água - no trabalho $\mathrm{C} 3$, para a argamassa tradicional de cimento, verificouse um aumento (de 7\% a 20\%) da permeabilidade ao vapor de água após aplicação nos suportes. No caso da argamassa pré-dosada de cimento, a permeabilidade subiu $4 \%$ e $16 \%$ para os suportes de acrílico e concreto, respetivamente, e desceu $11 \%$ para o suporte de tijolo. Já a argamassa pré-dosada de cal aérea viu a sua permeabilidade diminuir (de $10 \%$ a $21 \%$ ) para todos os suportes. No trabalho C4 observou-se também um aumento (de $10 \%$ a $25 \%$ ) da permeabilidade ao vapor de água da argamassa tradicional de cimento após aplicação nos suportes. Por sua vez, a permeabilidade da argamassa tradicional de cal hidráulica diminuiu (cerca de 10\%) após aplicação no suporte de tijolo e aumentou (cerca de 14\%) no suporte de concreto.

\section{Influência das condições de aplicação e de cura nas características das argamassas}

(a) condições de preparação do suporte - para as argamassas de cimento, verificou-se, nos trabalhos C2 e C3, uma tendência de diminuição (de $4 \%$ a 55\%) da sua capacidade de absorção de água (avaliada através dos ensaios de permeabilidade à água líquida e de absorção de água por capilaridade, respetivamente) quando se passa de uma condição sem umedecimento prévio para uma condição com umedecimento prévio. Isso deverá ser explicado pelo fato de a condição sem umedecimento prévio permitir uma sucção muito rápida da água da argamassa provocando a sua dessecação e, provavelmente, alguma microfissuração, o que favorece a penetração de água. A imersão do suporte em água, feita em C2, ao saturar os poros, reduz significativamente a sucção, o que leva a um aumento da capacidade de absorção de água da argamassa relativamente à condição de umedecimento prévio (chegando a valores três vezes superiores no caso da argamassa tradicional de cimento aplicada em tijolo). Importa referir que para a argamassa pré-dosada de cimento estudada em C2 e para a argamassa pré-dosada de cal aérea estudada em C3 não se verificaram tendências claras na variação dos resultados, o que deverá estar relacionado com a presença de hidrófugos e retentores de água nas suas composições. No que diz respeito à aplicação prévia de chapisco, feita em C4, não se observaram grandes alterações do comportamento da argamassa tradicional de cimento relativamente à condição com umedecimento prévio. No caso da argamassa tradicional de cal hidráulica, os suportes com chapisco levaram a uma maior diminuição na porosidade (reduções de $23 \%$ a $32 \%$ ).

(b) número de camadas e espessura das argamassas - no trabalho $\mathrm{C} 1$ verificou-se que a influência do número de camadas da argamassa tradicional de cimento é bastante significativa para o suporte de tijolo, enquanto para o suporte de concreto esse fator é quase irrelevante. De fato, para as argamassas aplicadas no suporte de tijolo, observou-se um decréscimo acentuado da permeabilidade à água líquida quando se passa da solução com uma camada para a solução com duas ou três camadas (redução de $83 \%$ e $74 \%$, respetivamente). Isso pode ser explicado pela maior dificuldade na passagem de água pelas interfaces das várias camadas. No trabalho $\mathrm{C} 1$ verificou-se ainda que a influência da espessura da argamassa pré-dosada de cimento é pouco relevante para o suporte de tijolo, enquanto para o suporte de concreto observa-se uma permeabilidade à água líquida 79\% superior para a argamassa de maior espessura. Isso poderá estar relacionado com a menor sucção exercida pelo suporte de concreto, que se torna especialmente ineficaz para camadas de maior espessura.

(c) condições de cura - no trabalho C3, para os modelos sem preparação prévia do suporte, adotaram-se condições de cura corrente e envelhecimento acelerado. $\mathrm{Na}$ argamassa tradicional de cimento ocorreu, com o envelhecimento, um aumento muito ligeiro da massa volúmica e uma diminuição de $3 \%$ a $14 \%$ da 
porosidade aberta. $\mathrm{Na}$ argamassa pré-dosada de cal aérea verificou-se uma diminuição muito pequena na massa volúmica e um aumento significativo (de 15\% a 73\%) na porosidade. Já para a argamassa pré-dosada de cimento não se observou uma tendência definida. Quanto ao coeficiente de absorção de água, as alterações foram consistentes com o verificado para a porosidade aberta. Observou-se também que, no geral, o envelhecimento reduz a permeabilidade ao vapor de água das argamassas (reduções até 33\%). No trabalho $\mathrm{C} 1$ avaliou-se o comportamento das argamassas aplicadas nos suportes aos 28, 60 e 90 dias. No trabalho C2 este estudo foi feito aos 28 e 90 dias. No geral, em ambos os trabalhos, observou-se, com o passar do tempo, uma tendência para o aumento da permeabilidade à água líquida das argamassas aplicadas, que poderá estar relacionada com o surgimento de microfissuração por retração.

\section{Conclusões}

Os resultados obtidos nas campanhas experimentais analisadas permitiram confirmar que, de fato, as propriedades dos suportes e as condições de aplicação influenciam as características das argamassas de revestimento aplicadas. Concluiu-se que a aplicação das argamassas nos suportes leva à alteração da sua estrutura porosa, com redução da porosidade aberta e, consequentemente, da capacidade de absorção de água, sendo que, quanto maior a capacidade de absorção de água do suporte, maior será a sua influência no desempenho da argamassa. Verificou-se também que a preparação do suporte com umedecimento prévio conduz aos melhores resultados em termos de comportamento das argamassas no estado endurecido, face à água líquida. Os resultados demonstraram que o número de camadas para a argamassa tradicional de cimento e o suporte de tijolo tem um efeito significativo na capacidade de absorção de água, devendo-se optar por uma solução multicamada; por outro lado, a espessura da argamassa pré-dosada de cimento é relevante para o suporte de concreto, não se devendo optar por grandes espessuras. Verificou-se também que as argamassas pré-dosadas (especialmente as de cimento) tendem a apresentar alterações de comportamento diferente devido à provável presença de hidrófugos na sua composição.

\section{Referências}

AGUIAR, J. B.; CRUZ, M. D. A study of the adhesion between hydraulic mortars and concrete. Journal of Adhesion Science and Technology, v. 12, n. 11, p. 1243-1251, 1998.

ARROMBA, J. Influência do suporte no desempenho de rebocos aplicados em suportes de tijolo e betão recorrendo a técnicas de ensaio in-situ. Lisboa, 2011. Dissertação (Mestrado em Engenharia Civil) Instituto Superior Técnico, Lisboa, 2011.

CARVALHO JUNIOR, A. N. Avaliação da aderência dos revestimentos argamassados: uma contribuição à identificação do sistema de aderência mecânico.Belo Horizonte, 2002. Tese (Doutorado em Engenharia Metalúrgica e de Minas) Pós-Graduação em Engenharia Metalúrgica e de Minas, Universidade Federal de Minas Gerais, Belo Horizonte, 2002.

COMITÉ EUROPÉEN DE NORMALISATION. EN 1015-10: methods of test for mortar for masonry: part 10: determination of dry bulk density of hardened mortar. Bruxelas, 1999.

COMITÉ EUROPÉEN DE NORMALISATION. EN 1015-18: methods of test for mortar for masonry: part 18: determination of water absorption coefficient due to capillary action of hardened mortar. Bruxelas, $2002 \mathrm{a}$.

COMITÉ EUROPÉEN DE NORMALISATION. EN 1015-19: methods of test for mortar for masonry: part 19: determination of water vapour permeability of hardened rendering and plastering mortars. Bruxelas, 1998.

COMITÉ EUROPÉEN DE NORMALISATION. EN 1015-21: methods of test for mortar for masonry: part 21: determination of the compatibility of one-coat rendering mortars with substrates. Bruxelas, $2002 \mathrm{~b}$.

COMITÉ EUROPÉEN DE NORMALISATION. EN 15801: conservation of cultural property: test methods: determination of water absorption by capillarity. Bruxelas, 2009.

COMITÉ EUROPÉEN DE NORMALISATION. EN 16322: conservation of cultural heritage: test methods: determination of drying properties. Bruxelas, 2013.

COMITÉ EUROPÉEN DE NORMALISATION. EN 772-11: methods of test for masonry units: determination of water absorption of aggregate concrete, manufactured stone and natural stone masonry units due to capillary action and the initial rate of water absorption of clay masonry units. Bruxelas, 2000. 
COMITÉ EUROPÉEN DE NORMALISATION. EN ISO 12572: hygrothermal performance of building materials and products: determination of water vapor transmission properties. Bruxelas, 2001.

COSTA, E. B. C.; JOHN, V. M. Aderência substrato-matriz cimentícia: estado da arte. In: SIMPÓSIO BRASILEIRO DE TECNOLOGIA DE ARGAMASSAS, 9., Belo Horizonte, 2011. Anais [...] Belo Horizonte, 2011.

COSTA, E. B.; CARASEK, H. Influência dos parâmetros de ensaio na determinação da resistência de aderência de revestimentos de argamassa. Ambiente Construído, Porto Alegre, v. 9, n. 4, p. 17-35, out./dez. 2009.

GONÇALVES, A. Estudo da influência dos factores de aplicação no desempenho de argamassas de revestimento recorrendo a técnicas de ensaio in-situ. Lisboa, 2010. Dissertação (Mestrado em Engenharia Civil) - Instituto Superior Técnico, Lisboa, 2010.

INSTITUTO PORTUGUÊS DA QUALIDADE. NP EN 1936: métodos de ensaio para pedra natural. Determinação das massas volúmicas real e aparente e das porosidades total e aberta. Caparica, 2008.

INTERNATIONAL ORGANIZATION FOR STANDARDIZATION. ISO 15148: hygrothermal performance of building materials and products: determination of water absorption coefficient by partial immersion. Geneva, 2002.

LABORATÓRIO NACIONAL DE ENGENHARIA CIVIL. Ficha de ensaio FE Pa 39.1: revestimentos de paredes: ensaio de absorção de água sob baixa pressão. Lisboa, 2002.

MATIAS, G. Argamassas de reabilitação com resíduos de cerâmica. Coimbra, 2014. Tese (Doutoradoem Engenharia Civil) - Escola de Engenharia, Universidade de Coimbra, Coimbra, 2014.

MOROPOULOU, A.; BAKOLAS, A.; BISBIKOU, K. Physico-chemical adhesion and cohesion bonds in joint mortars im parting durability to the historic structures. Construction and Building Materials, v. 14, $\mathrm{n}$. 1, p. 35-46, feb. 2000.

NICOT, P. Inter actions mortier-support: éléments déterminants des performances et de l'adhérence d'unmortier. Toulouse, 2008. Tese (Doutoramento em Engenharia Civil) - Université de Toulouse, Toulouse, 2008.

PALMER, L. A.; PARSONS, D. A. A study of the properties of mortars and bricks and their relation to bond. Bureau of Standards Journal of Research, v. 12, n. 5, p. 609-644, may 1934.

PAULO, D. L. Estudo de fatores que podem influenciar as características das argamassas após aplicação nos suportes. Coimbra, 2019. Dissertação (Mestrado em Engenharia Civil) - Faculdade de Ciências e Tecnologia, Universidade de Coimbra, Coimbra, 2019.

POLITO, G.; CARVALHO JUNIOR, A. N.; BRANDÃO, P. R. G. Caracterização microestrutural da interface argamassa mista/bloco cerâmico. Construindo, Belo Horizonte, v. 2, n. 2, p. 11-17, jul./dez. 2010.

SZEMEREY-KISS, B.; TÖRÖK, Á. Failure mechanisms of repair mortar stone interface assessed by pulloff strength tests. Bulletin Engineering Geology Environment, v. 76, p. 159-167, 2017.

TORRES, I. Influência da absorção do suporte na argamassa de revestimento. Porto, 2014. Relatório (Pós-Doutoramento em Engenharia Civil) - Faculdade de Engenharia da Universidade do Porto, Porto, 2014. WU, S. Polymer interface andadhesion. New York: M. Dekker, 1982.

\section{Agradecimentos}

Estudo enquadrado no projeto IF Mortar (POCI-01-0145-FEDER-032223, PTDC/ECI-EGC/32223/2017), inserido no programa Portugal 2020, financiado pelo FEDER através do programa POCI (Programa Operacional Competitividade e Internacionalização) e pela FCT (Fundação para a Ciência e a Tecnologia), na sua componente de Orçamento de Estado. Os autores agradecem ao CERIS/IST e à FCT. 


\section{Maria Isabel Morais Torres}

Instituto de Invesrtigação e Desenvolvimento Tecnológico para a Construção, Energia, Ambiente e Sustentabilidade | Departamento de Engenharia Civil, Associação para o Desenvolvimento da Aerodinâmica Industrial, Laboratório Associado de Energia, Transportes e Aeronáutica | Universidade de Coimbra | RuaLuis Reis dos Santos, 290 | Coimbra - Portugal | 3030-790 | Tel.: + (351) 918951150 | E-mail: itorres@dec.uc.pt

\section{Inês Flores-Colen}

Civil Engineering Research and Innovation for Sustainability, Departamento de Engenharia Civil, Arquitectura e Georecursos, Instituto Superior Técnico | Universidade de Lisboa | Av. Rovisco Pais | Lisboa - Portugal | 1049-001 | Tel.: + (351) 919954245 | E-mail: ines.flores.colen@tecnico.ulisboa.pt

\section{Dora Susana Gomes da Silveira}

Instituto de Invesrtigação e Desenvolvimento Tecnológico para a Construção, Energia, Ambiente e Sustentabilidade | Rua Pedro Hispano | Coimbra - Portugal | 3030-289 | Tel: + (351) 969770589 | E-mail: dora.silveira@itecons.uc.pt

\section{Rafael Travincas Pinto}

Civil Engineering Research and Innovation for Sustainability, Instituto Superior Técnico | Universidade de Lisboa | Av. Rovisco Pais, 1 | Lisboa - Portugal | 1049-001 | Tel.: + (351) 917832491 | E-mail: rafaeltravincas@gmail.com

\section{Gina Maria Lourenço Matias}

Instituto de Invesrtigação e Desenvolvimento Tecnológico para a Construção, Energia, Ambiente e Sustentabilidade | Associação para o Desenvolvimento da Aerodinâmica Industrial, Laboratório Associado de Energia, Transportes e Aeronáutica| Rua Pedro Hispano | Coimbra - Portugal | 3030-289 | Tel.: + (351) 914801314 | E-mail: ginamatias@itecons.uc.pt

\section{Ambiente Construído}

Revista da Associação Nacional de Tecnologia do Ambiente Construído Av. Osvaldo Aranha, $99-3^{\circ}$ andar, Centro

Porto Alegre - RS - Brasil

$$
\text { CEP } 90035-190
$$

Telefone: +55 (51) 3308-4084

Fax: +55 (51) 3308-4054

www.seer.ufrgs.br/ambienteconstruido

E-mail: ambienteconstruido@ufrgs.br 